\title{
EFEITO DA TEMPERATURA DE REVENIMENTO NO AÇO ASTM A 522 UTILIZADO NA INDÚSTRIA DE PETRÓLEO E GÁS *
}

\author{
Bruna Helena Malovini Loiola ${ }^{1}$ \\ Pedro Gabriel Bonella de Oliveira² \\ Rosana Vilarim da Silva ${ }^{3}$ \\ André Itman Filho ${ }^{4}$
}

\section{Resumo}

Os aços ligados ao níquel especificados pela norma ASTM A 522 são utilizados na fabricação de válvulas, flanges e conexões de tubos, na indústria automotiva, na construção civil e na área naval. $\mathrm{Na}$ indústria de petróleo e gás, o material requer desempenho adequado para resistir às altas pressões, ao ambiente corrosivo e à abrasão. Considerando os efeitos do desgaste nas válvulas e flanges, este trabalho tem como objetivo avaliar o efeito da temperatura de revenimento na microestrutura e dureza do aço. Amostras submetidas à têmpera a $860^{\circ} \mathrm{C}$ e ao revenimento na faixa de 380 a $630^{\circ} \mathrm{C}$ proporcionaram resultados que mostram uma microestrutura predominante de bainita após têmpera e redução da dureza com o aumento da temperatura de revenimento devido ao alívio de tensão.

Palavras-chave:Aços ligados ao níquel; Indústria de petróleo e gás; Aço ASTM A 522.

\section{EFFECT OF TEMPERING TEMPERATURES ON ASTM A 522 STEEL USED IN THE OIL AND GAS INDUSTRY}

\begin{abstract}
The nickel steels specified by ASTM A 522 are used in the manufacture of valves, flanges and connections for tube in the automotive industry, construction and shipbuilding. In the oil and gas industry, the material requires adequate performance to withstand high pressures, corrosive environment and abrasion. Considering the effects of wear of the valves and flanges, this research aims to evaluate the effect of the tempering temperatures on the microstructure and hardness of the steel. The pieceworks were subjected to quenching $\left(860^{\circ} \mathrm{C}\right)$ and to tempering $\left(380-630^{\circ} \mathrm{C}\right)$. The results are about the predominance of bainite microstructure after quenching, and the decrease of the microhardness in accordance with the increase of the tempering temperature due to the internal stress relief.
\end{abstract}

Keywords: Nickel steel; Oil and gas industry; ASTM A 522 steel

1 Graduanda em Engenharia Metalúrgica, Instituto Federal do Espírito Santo - Ifes, Vitória, ES, Brasil.

2 Mestrando em Engenharia Metalúrgica e de Materiais, Instituto Federal do Espírito Santo - Ifes, Vitória, ES, Brasil.

3 Doutora em Ciência e Engenharia de Materiais pela EESC-USP, professora do Instituto Federal do Espírito Santo - Ifes, Vitória, ES, Brasil.

4 Doutor em Ciência e Engenharia de Materiais pela UFScar, professor do Instituto Federal do Espírito Santo - Ifes, Vitória, ES, Brasil. 


\section{INTRODUÇÃO}

Nos últimos anos houve um crescimento da demanda mundial por tubos utilizados na construção de dutos de grande vazão, para indústria de petróleo e gás natural. No Brasil, informações da Agência Nacional de Petróleo revelam que na década passada a produção de petróleo aumentou $75 \%$ e no mesmo período o consumo de gás aumentou $120 \%$. Há previsão para volumes de 4,0 milhões de barris de petróleo/dia em 2020 [1].

O crescimento no consumo de petróleo e gás natural tem estimulado o desenvolvimento de novos aços para aumentar a vida útil das linhas de válvulas, juntas, conexões e flanges a serem instaladas em tubos. $O$ ambiente na indústria petroquímica exige aços que precisam ter características específicas para resistir à alta pressão, à temperatura na descompressão do gás de aproximadamente $-70 \stackrel{\circ}{\circ}$ e aos gases corrosivos como $\mathrm{CO}_{2}$ e $\mathrm{H}_{2} \mathrm{~S}[2,3]$.

Uma das alternativas para fabricação de válvulas, flanges e acessórios para a área petrolífera é o aço ASTM A 522 que contém em torno de 10\% de níquel como principal elemento na composição química. Este aço é caracterizado por apresentar boa resistência mecânica associada à soldabilidade, tenacidade à fratura, ductilidade, resistência à corrosão e capacidade de operar em profundidade de aproximadamente 2000 metros com pressão estática por volta de $600 \mathrm{kgf} / \mathrm{cm}^{2}[4,5]$. Estas condições obrigaram a melhoria dos projetos de fabricação dos aços e um estudo sistemático das composições químicas adequadas às qualidades exigidas. $\mathrm{Na}$ fabricação dos componentes e acessórios com maior complexidade geométrica os quais são utilizados em dutos para transporte de petróleo e gás, o processo de forjamento é o mais adequado. A técnica de forjamento produz peças com excelentes propriedades mecânicas e um menor custo de fabricação. A perda de material é mínima, pois o produto forjado possui as dimensões próximas ao produto final. Em geral, os componentes forjados são submetidos posteriormente aos tratamentos térmicos, para apresentarem a resistência e tenacidade necessárias [6]. Dessa forma, é necessária a têmpera e o revenimento para atender às solicitações mecânicas especificadas na norma ASTM A 522 e no caso onde a resistência ao desgaste é um fator considerável no projeto, o conhecimento da dureza é importante.

\section{MATERIAIS E MÉTODOS}

\subsection{Corte e preparação das amostras}

Amostras do aço ASTM A 522 de uma barra forjada submetida ao tratamento térmico de recozimento foram cortadas com $15 \mathrm{~mm}$ de lado no disco abrasivo no Laboratório de Metalografia do Ifes. A composição química do material apresentada na Tabela 1 está de acordo com as especificações da norma.

Tabela 1. Composição química do aço ao níquel forjado

\begin{tabular}{cccccccc}
\hline $\mathbf{C}$ & $\mathbf{M n}$ & $\mathbf{P}$ & $\mathbf{S}$ & $\mathbf{S i}$ & $\mathbf{N i}$ & $\mathbf{C r}$ & $\mathbf{M o}$ \\
\hline 0,07 & 0,44 & 0,004 & 0,002 & 0,17 & 9,2 & 0,17 & 0,05 \\
\hline
\end{tabular}




\subsection{Tratamentos térmicos de têmpera e revenimento}

As amostras foram submetidas ao tratamento térmico de têmpera a $860{ }^{\circ} \mathrm{C}$ durante 40 minutos em um forno tipo mufla e resfriadas em água. Posteriormente, foram revenidas nas temperaturas de $380,440,480,590$ e $630^{\circ} \mathrm{C}$ durante 40 minutos.

\subsection{Preparação metalográfica convencional das amostras tratadas}

As amostras foram preparadas conforme os métodos tradicionais de metalografia usando lixas de 80, 180, 220, 320, 400, 600, 1000 e 1200 e polimento em disco de feltro com pasta de alumina $0,30 \mu \mathrm{m}$. Em seguida, foram imersas em uma solução de Nital $2 \%$ para observação da microestrutura em um microscópio ótico confocal (MOC).

\subsection{Medidas de dureza}

As medidas de dureza foram realizadas em um microdurômetro Vickers modelo HVS 1000 A com carga de $1,96 \mathrm{~N}$.

\section{RESULTADOS E DISCUSSÃO}

A Figura 1 (a) mostra a microestrutura do aço temperado após ataque com Nital. Há um predomínio de bainita na forma de tiras paralelas por partículas descontínuas de cementita. Em razão do baixo teor de carbono, a ferrita apresenta ripas finas. A solubilidade do carbono na ferrita bainítica, cinza escura, é muito menor do que na austenita. Assim o carbono é rejeitado para a austenita em torno das ripas de ferrita bainítica [7]. A Figura 1 (a) é similar à microestrutura da Figura 1 (b) de um aço ao níquel temperado a $800^{\circ} \mathrm{C}$ [8]. A letra B indica bainita, as letras AF indicam ferrita acicular e GBF ferrita de contorno de grão.

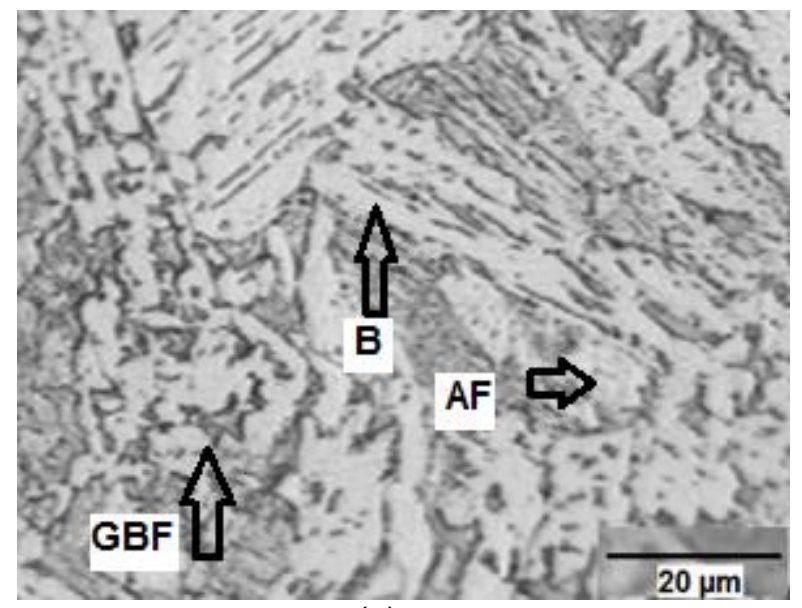

(a)

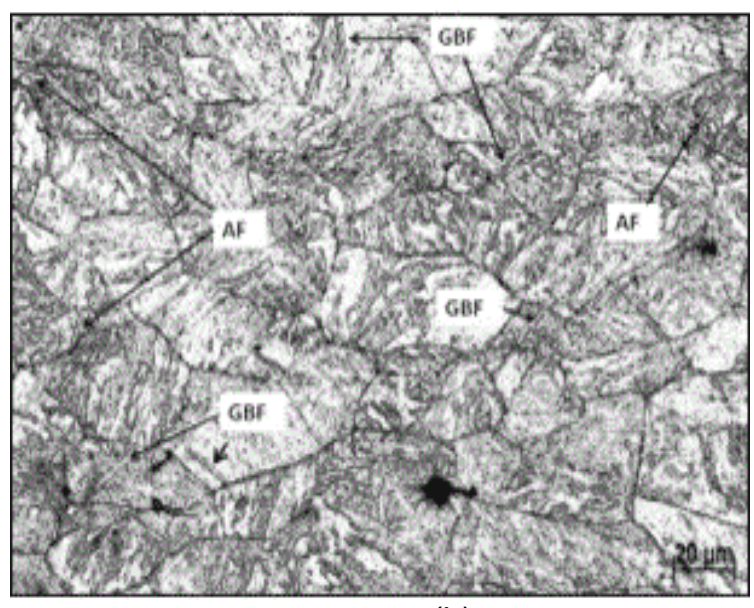

(b)

Figura 1. (a) Aço temperado com predomínio de bainita em tiras paralelas. Ataque com Nital $2 \%$ e MOC. (b) Aço ASTM A 522 temperado com ferrita acicular e ferrita de contorno de grão.

As Figuras 2 (a) e (b) apresentam as microestruturas do aço revenido a 380 e a 440 ${ }^{\circ} \mathrm{C}$, respectivamente. Após o revenimento a quantidade de bainita diminui. 


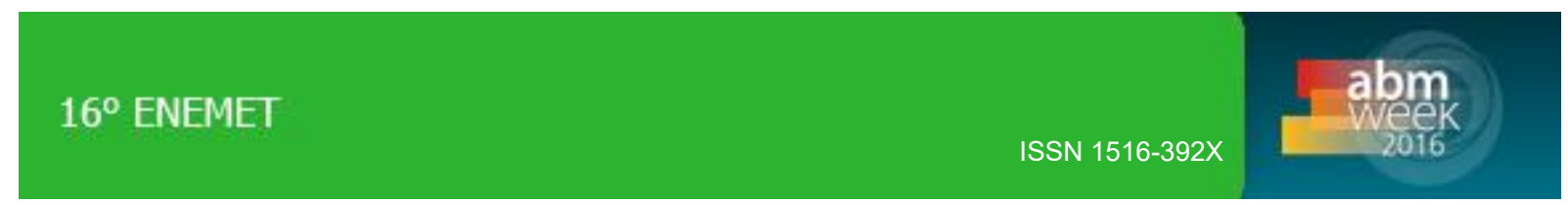

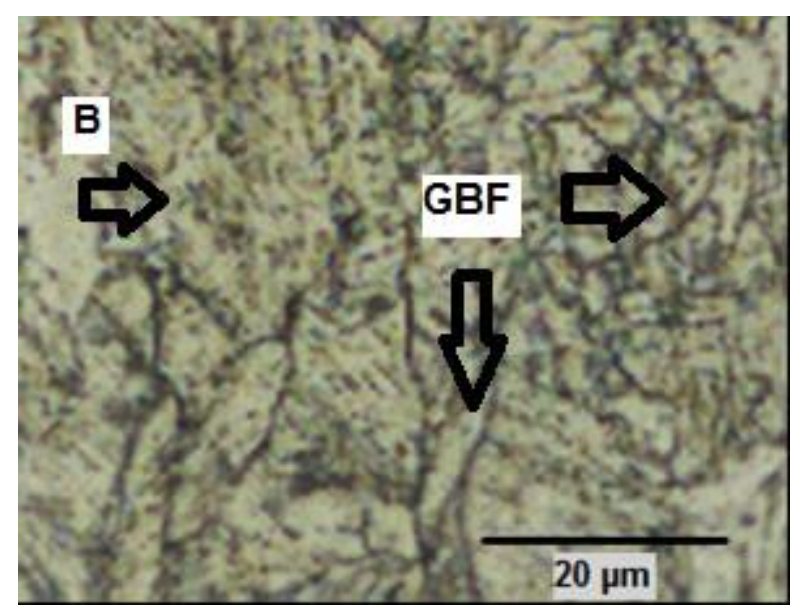

(a)

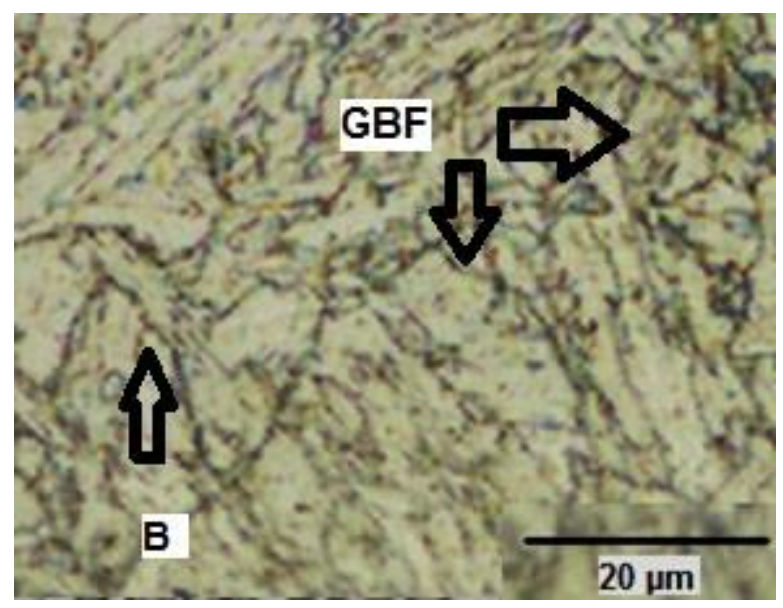

(b)

Figura 2. Microestrutura após revenimento a $380^{\circ} \mathrm{C}$ e $440{ }^{\circ} \mathrm{C}$.do aço ASTM A 522 TP I. Ataque com Nital $2 \%$ e MOC.

As Figuras 3 (a) e (b) mostram microestruturas após o revenimento, respectivamente, a 480 e a $590^{\circ} \mathrm{C}$. Neste caso há uma maior quantidade de carbonetos precipitados na matriz, representados por $\mathrm{C}$, detectados após análise no microscópio eletrônico de varredura (MEV), como na Figura 6.

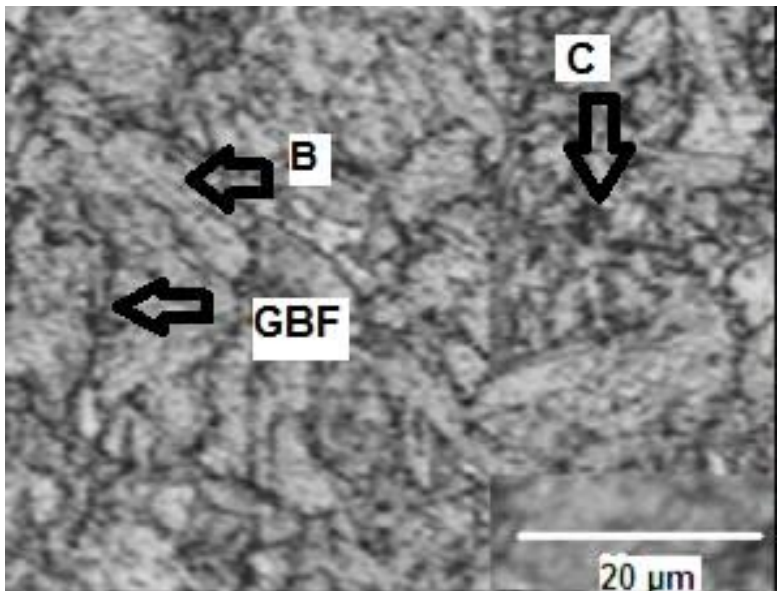

(a)

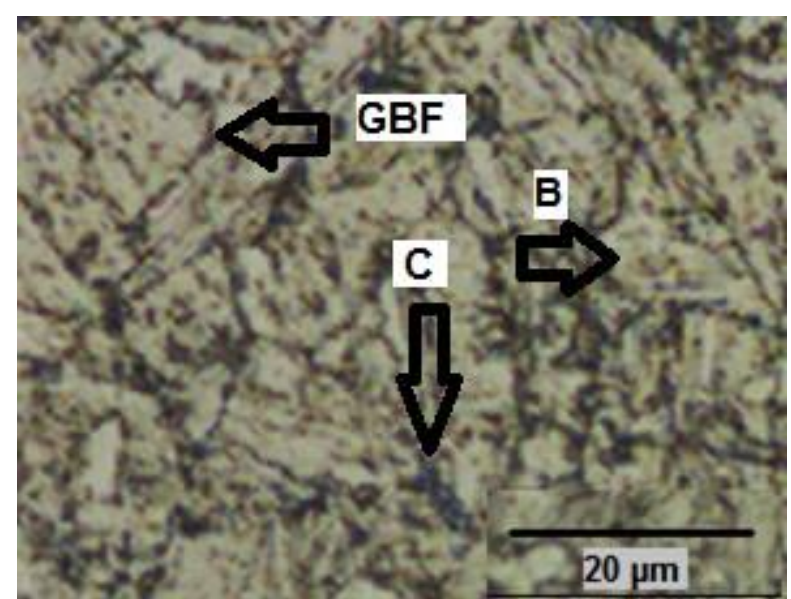

(b)

Figura 3. Microestruturas após revenimento a 480 (a) e (b) $590^{\circ} \mathrm{C}$. Ataque com Nital $2 \%$ e MOC.

A microestrutura apresentada na Figura 4 é do aço revenido a $630{ }^{\circ} \mathrm{C}$ que mostra maior número de carbonetos precipitados devido ao aumento da difusão de carbono que favorece a precipitação. Os carbonetos estão destacados pelas setas, nos contornos de gãos e entre as ripas ferríticas. 


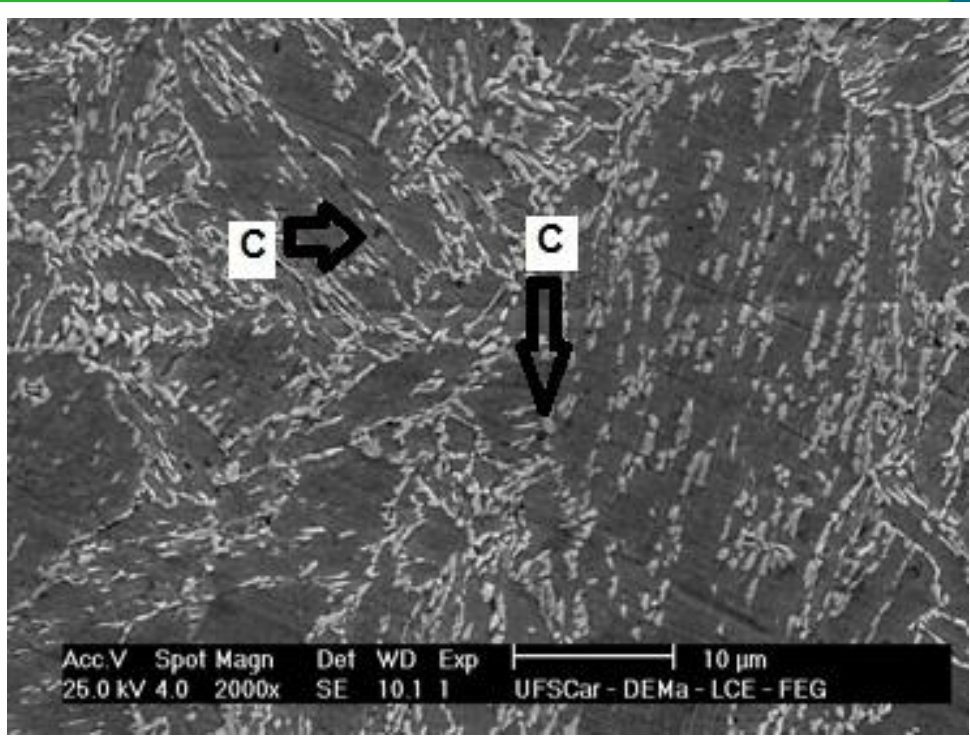

Figura 4. Microestruturas após revenimento a $630^{\circ} \mathrm{C}$. Ataque com Nital $2 \%$ e MEV.

O gráfico da Figura 5 apresenta as medidas de durezas em função da temperatura de revenimento com as barras dos desvios padrões. Observa-se uma redução da dureza com o aumento da temperatura de revenimento. O revenimento favorece a diminuição da dureza porque o carbono saturado da martensita precipita como carboneto e promove o alívio das tensões internas [9].

\section{Curva de Revenimento ASTM A 522}

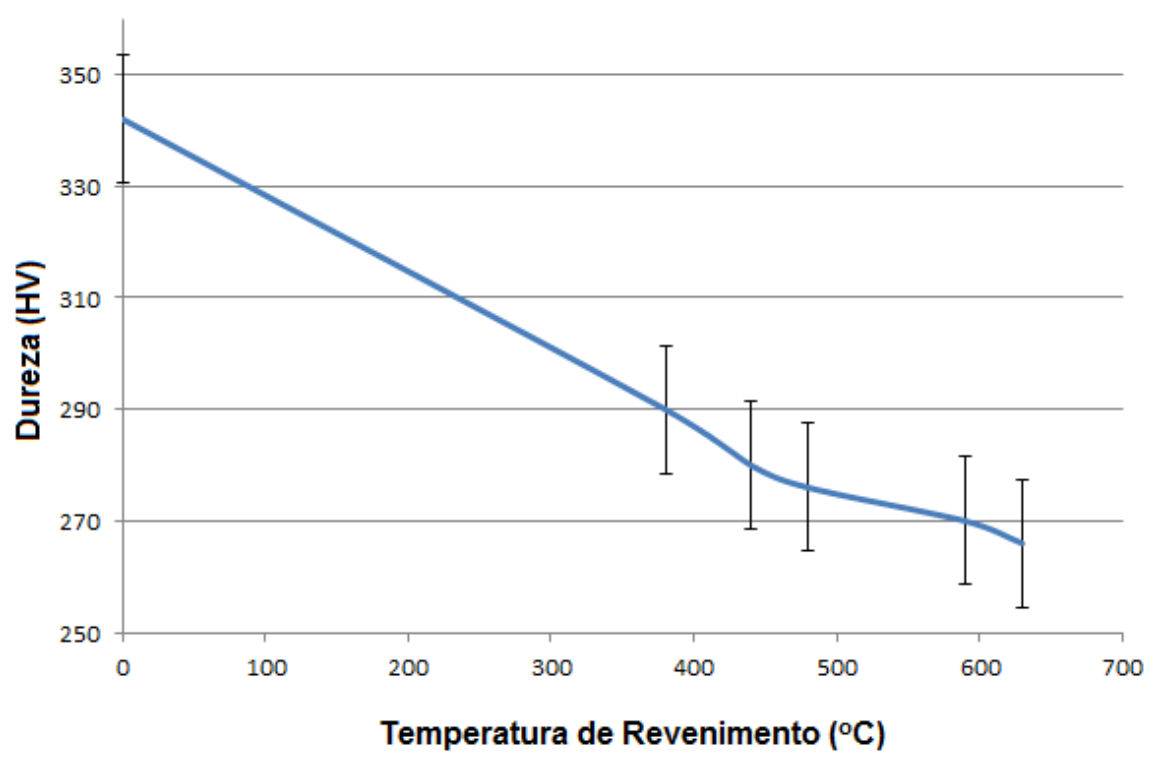

Figura 5. Efeito da temperatura de revenimento na dureza do aço ASTM A 522. Média de cinco medidas de dureza em cada condição.

\section{CONCLUSÃo}

- O aço ASTM A 522 apresenta uma microestrutura de bainita com precipitação de carbonetos após têmpera e revenimento;

- A dureza diminui linearmente até a temperatura de revenimento de $480^{\circ} \mathrm{C}$ e após este valor tende a estabilizar. 


\section{Agradecimentos}

Os autores agradecem ao CNPq (Processo 468244/2014-0) pelo auxílio financeiro, ao Ifes pela bolsa de Iniciação Científica e ao Grupo Metal pela amostra do aço.

\section{REFERÊNCIAS}

1 Agência Nacional de Petróleo, Gás Natural e Biocombustíveis (ANP). A ANP. 2011 [acesso em 22 de maio de 2015]. Disponível em: http://www.anp.gov.br/?id=592

2 American Society for Testing and Materials (ASTM) A 522/A 522M. Standard Specification for Forged or Rolled 8 and $9 \%$ Nickel alloy steel flanges, fittings, valves, and parts for low-temperature service. 2001; 1-4.

3 American Society for Metals handbook. (9): ASM; 1987.

4 Barbosa C. O Papel das LRCs. Ligas Resistentes a Corrosão contendo Níquel no PréSal. 2012. [acesso em 07 de dezembro de 2015]. 13-14. Disponível em:

http://www.icz.org.br/portaldoniquel/arquivos/celso_barbosa-villares-metals.pdf.

5 American Society for Metals Handbook. Seção Publication Information and Contributors (PDF). 2005:1: 653-690.

6 Colpaert, H. Metalografia dos Produtos Siderúrgicos Comuns. 4 ed. São Paulo. Bluncher; 2008.

7 The Welding Institute. What are the microstructural constituents Austenite, Martensite, Bainite, Pewrlite and Ferrite?2010. [acesso em 14 de dezembro de 2015]. Disponível em: http://www.twi-global.com/technical-knowledge/faqs/material-faqs/faq-what-are-themicrostructural-constituents-austenite-martensite-bainite-pearlite-and-ferrite/>

8 InTec. Ultrahigh Strength Steel: Development of Mechanical Properties Through Controlled Cooling (PDF). Alemanha, 2011.

9 Silva, ALC; Mei, PR. Aços e Ligas Especiais. 2 ed. São Paulo: Edgard Blucher; 2006; 2:51-56. 